\title{
The maximal domain for the revelation principle when preferences are menu dependent
}

Citation for published version (APA):

Saran, R. R. S. (2008). The maximal domain for the revelation principle when preferences are menu dependent. METEOR, Maastricht University School of Business and Economics. METEOR Research Memorandum No. 023 https://doi.org/10.26481/umamet.2008023

Document status and date:

Published: 01/01/2008

DOI:

10.26481/umamet.2008023

Document Version:

Publisher's PDF, also known as Version of record

\section{Please check the document version of this publication:}

- A submitted manuscript is the version of the article upon submission and before peer-review. There can be important differences between the submitted version and the official published version of record.

People interested in the research are advised to contact the author for the final version of the publication, or visit the DOI to the publisher's website.

- The final author version and the galley proof are versions of the publication after peer review.

- The final published version features the final layout of the paper including the volume, issue and page numbers.

Link to publication

\footnotetext{
General rights rights.

- You may freely distribute the URL identifying the publication in the public portal. please follow below link for the End User Agreement:

www.umlib.nl/taverne-license

Take down policy

If you believe that this document breaches copyright please contact us at:

repository@maastrichtuniversity.nl

providing details and we will investigate your claim.
}

Copyright and moral rights for the publications made accessible in the public portal are retained by the authors and/or other copyright owners and it is a condition of accessing publications that users recognise and abide by the legal requirements associated with these

- Users may download and print one copy of any publication from the public portal for the purpose of private study or research.

- You may not further distribute the material or use it for any profit-making activity or commercial gain

If the publication is distributed under the terms of Article $25 \mathrm{fa}$ of the Dutch Copyright Act, indicated by the "Taverne" license above, 


\section{Rene Saran}

The Maximal Domain for the Revelation Principle when Preferences are Menu Dependent

$\mathrm{RM} / 08 / 023$

JEL code: C72, D78

\section{METE@R}

Maastricht research school of Economics of TEchnology and ORganizations

Universiteit Maastricht

Faculty of Economics and Business Administration P.O. Box 616

NL - 6200 MD Maastricht

phone : ++31433883830

fax $\quad:++31433884873$ 


\title{
The Maximal Domain for the Revelation Principle when Preferences are Menu Dependent*
}

\author{
Rene $\operatorname{Saran}^{\dagger}$ \\ Maastricht University, Maastricht, The Netherlands
}

April 16, 2008

\begin{abstract}
We extend the domain of preferences to include menu-dependent preferences and characterize the maximal subset of this domain in which the revelation principle holds. Minimax-regret preference is shown to be outside this subset.
\end{abstract}

Keywords: Revelation Principle; Menu-dependent Preferences; Minimaxregret

JEL: C72; D78

\section{Introduction}

The revelation principle is the foundation of the theory of mechanism design (see, for example, Dasgupta, Hammond and Maskin (1979), Myerson (1979)). Applied to an environment of incomplete information, it states that for any Bayesian-Nash equilibrium of any mechanism there exists an outcome-equivalent Bayesian-Nash equilibrium of a direct mechanism in which all players report their respective types truthfully. Thus, the revelation principle greatly simplifies the search for "optimal" mechanisms; we only need to search in the set of incentive compatible direct mechanisms.

The notion of Bayesian-Nash equilibrium assumes that players' preferences satisfy the von Neumann-Morgenstern axioms and thus, are represented by expected-utility

${ }^{*}$ I thank Jean-Jacques Herings, Flip Klijn, Takashi Kunimoto, Ronald Peeters, Roberto Serrano and Markus Walzl for helpful suggestions and discussions.

${ }^{\dagger}$ Email address: r.saran@algec.unimaas.nl; Tel: +31-43-3883763; Fax: +31-43-3884878 
functions (von Neumann and Morgenstern (1944)). As nonstandard preferences become standard in the literature, it is pertinent to ask whether the revelation principle holds if players are not expected-utility maximizers. ${ }^{1}$ In this paper, we extend the domain of preferences to include menu-dependent preferences, i.e., preference of a player can depend on the set of available alternatives (which is called a menu). ${ }^{2}$ We characterize the maximal subset of this domain in which the revelation principle holds - this requires a modified notion of the equilibrium. This subset is the set of preference relations that satisfy what we call weak contraction consistency.

The setup is that of incomplete information in which a state is a realization of a type profile. The set of states is commonly known; however, each player privately knows only her type. An alternative is a Savage act that specifies an outcome for every possible realization of the state. We assume that for any menu, each type of each player has a complete preference relation over the Savages acts that are elements of that menu. The preference relation over two Savage acts can be different in different menus that contain these two acts; thus, the preferences can be menu dependent.

We provide two results. First, if the preferences of all types of all players satisfy weak contraction consistency, then the revelation principle holds. Second, if the preference of any type of any player does not satisfy weak contraction consistency, then there exists a preference profile such that the revelation principle does not hold. In this sense, the set of preferences that satisfy weak contraction consistency for all types of all players is the maximal domain in which the revelation principle holds. We also show that it is not possible to strengthen the second result; thus, if the preference of a type of a player does not satisfy weak contraction consistency, then the revelation principle can hold for some preference profile.

Weak contraction consistency is weakening of contraction consistency. ${ }^{3}$ Contraction consistency requires that for any menu, a maximal element in that menu remains maximal after any contraction of the menu around that element (i.e., when the maximal element is available in the menu after the contraction). Weak contrac-

\footnotetext{
${ }^{1}$ The literature on implementation theory has also incorporated boundedly rational players; see, for example, Hurwicz (1986), Eliaz (2002) and Cabrales and Serrano (2007).

${ }^{2}$ Sen $(1993,1994)$ argues for the need to incorporate menu dependence in standard rational choice theory. Also see Sen (1997) for a formal analysis. Menu dependence of choice has been well documented in experimental studies; see, for example, Huber, Payne and Puto (1982), Simonson and Tversky (1992).

${ }^{3}$ Contraction consistency was originally introduced by Chernoff (1954) and has alternatively been termed Property $\alpha$ by Sen (1971). In its original formulation, contraction consistency is a property of the choice function. We adapt it to the primitive of our model, a preference relation.
} 
tion consistency weakens contraction consistency at two levels: first, the property must be satisfied by only a class of menus - instead of any menu - and secondly, it requires that a maximal element in a menu remains maximal after only a unique contraction - instead of any contraction - of the menu around that element (see Definition 2.1 for details).

Minimax regret is a menu-dependent preference relation that has been often studied in the literature starting with Savage (1951). According to minimax regret, each type of a player chooses the alternative that minimizes her maximum regret. Regret of choosing an alternative in a state is defined as the difference between the payoff that is obtained and the maximum payoff that could have been attained in that state; since the latter depends on the set of alternatives available in that state, the relation is menu dependent. Maximum regret of choosing an alternative is the maximum of these differences over all states of the world. We provide an example in which the minimax-regret preference relation does not satisfy weak contraction consistency and consequently, the revelation principle does not hold. ${ }^{4}$

We also provide an example in which the preference of each type of a player is menu dependent due to extremeness aversion (Simonson and Tversky (1992)) and satisfies weak contraction consistency.

In presenting our results, we assume that a type of a player has a preference relation over each menu, which is a set of Savage acts. A Savage act is an ex-ante lottery that specifies an outcome for each realization of all players' types. However, a type of a player plays only in the interim stage (when she knows her type) and thus, one might argue, she should "care" about interim lotteries that specify an outcome for each realization of other player's types instead of ex-ante lotteries. In the Appendix, we show that our results do not change with this alternative formulation.

The paper is organized as follows. We explain the model and collect all the results and examples in Section 2. Section 3 provides a brief conclusion. In the Appendix, we show that our results hold even if we assume that each type of each player "cares" about interim lotteries.

\section{Model and Results}

Let $N$ be the set of players. A type of player $i$ is denoted by $t_{i}$ and the set of types of player $i$ is $T_{i}$. Each player privately knows only her type. Let $T=\prod_{i \in N} T_{i}$ be

\footnotetext{
${ }^{4}$ It is known that the minimax-regret preference relation does not satisfy contraction consistency. See Chernoff (1954) for an example.
} 
the commonly known type space and $t$ be a type profile. $t_{-i}$ is a type profile of all players other than $i$ and $T_{-i}$ is the set of such profiles.

$A$ is the set of outcomes. $\triangle A$ denotes the set of probability measures on $A$. A Savage act is a function $f: T \rightarrow \Delta A$. Let $\mathcal{F}$ be the set of all Savage acts. A menu $F$ is a subset of $\mathcal{F}$.

Each type $t_{i}$ of each player $i$ has a complete preference relation $\succeq_{t_{i}}^{F}$ over each menu $F$. Let $\succ_{t_{i}}^{F}$ and $\sim_{t_{i}}^{F}$ be, respectively, the strict preference and indifference relations derived from $\succeq_{t_{i}}^{F}$. Let $\succeq_{t_{i}}=\left(\succeq_{t_{i}}^{F}\right)_{F \subseteq \mathcal{F}}$ and $\succeq_{i}=\left(\succeq_{t_{i}}\right)_{t_{i} \in T_{i}}$.

$N, T$ and $A$ are fixed throughout the paper. We call $\mathcal{E}=\left(\succeq_{i}\right)_{i \in N}$ to be the environment.

Given a menu $F$, let $\xi_{i}^{F}: T_{i} \rightarrow F$ be an arbitrary function and denote the set of such functions by $\Xi_{i}^{F}$. Let $\psi_{i}: T_{i} \rightarrow T_{i}$ be an arbitrary function and denote the set of such functions by $\Psi_{i}$.

For any $F \subseteq \mathcal{F}, \xi_{i}^{F} \in \Xi_{i}^{F}$ and $\psi_{i} \in \Psi_{i}$, define the Savage act $h_{\psi_{i}}^{\xi_{i}^{F}}$ as follows:

$$
h_{\psi_{i}}^{\xi_{i}^{F}}\left(t_{i}, t_{-i}\right) \equiv \xi_{i}^{F}\left(t_{i}\right)\left(\psi_{i}\left(t_{i}\right), t_{-i}\right), \forall\left(t_{i}, t_{-i}\right) \in T
$$

Thus, the outcome of the Savage act $h_{\psi_{i}}^{\xi_{i}^{F}}$ in state $\left(t_{i}, t_{-i}\right)$ is equal to the outcome of the Savage act $\xi_{i}^{F}\left(t_{i}\right)$ in state $\left(\psi_{i}\left(t_{i}\right), t_{-i}\right)$. Let $F\left(\xi_{i}^{F}\right)=\left\{h_{\psi_{i}}^{\xi_{i}^{F}} \mid \psi_{i} \in \Psi_{i}\right\}$.

For any $f \in \mathcal{F}$ and $\psi_{i} \in \Psi_{i}$, define the Savage act $f_{\psi_{i}}$ as follows:

$$
f_{\psi_{i}}\left(t_{i}, t_{-i}\right) \equiv f\left(\psi_{i}\left(t_{i}\right), t_{-i}\right), \forall\left(t_{i}, t_{-i}\right) \in T
$$

Let $F(f, i)=\left\{f_{\psi_{i}} \mid \psi_{i} \in \Psi_{i}\right\}$

Definition 2.1. We say that $\succeq_{t_{i}}$ satisfies weak contraction consistency (henceforth $W C C$ ) if the following holds: $\forall F \subseteq \mathcal{F}$ such that $F=\bigcup_{\xi_{i}^{F} \in \Xi_{i}^{F}} F\left(\xi_{i}^{F}\right)$ and $\forall f \in F$,

$$
f \succeq_{t_{i}}^{F} f^{\prime}, \forall f^{\prime} \in F \Longrightarrow f \succeq_{t_{i}}^{F(f, i)} f_{\psi_{i}}, \forall \psi_{i} \in \Psi_{i}
$$

For any $F \subseteq \mathcal{F}$ and $f \in F$, if $\xi_{i}^{F}\left(t_{i}\right)=f, \forall t_{i} \in T_{i}$, then $h_{\psi_{i}}^{\xi_{i}^{F}}=f_{\psi_{i}}, \forall \psi_{i} \in \Psi_{i}$ and thus, $F\left(\xi_{i}^{F}\right)=F(f, i)$. So, if $F=\bigcup_{\xi_{i}^{F} \in \Xi_{i}^{F}} F\left(\xi_{i}^{F}\right)$, then $F(f, i) \subseteq F$. Thus, we see that $W C C$ is a weakening of contraction consistency at two levels: first, the property must be satisfied by only a class of menus (menus $F$ which are equal to $\left.\bigcup_{\xi_{i}^{F} \in \Xi_{i}^{F}} F\left(\xi_{i}^{F}\right)\right)$ and second, it only requires that a maximal element $f$ remains maximal after a unique contraction of the menu around $f$ (which is $F(f, i)$ ).

A mechanism $\Gamma=\left(\left(M_{i}\right)_{i \in N}, g\right)$ defines the set of messages $M_{i}$ available to each 
player and the outcome $g: \prod_{i} M_{i} \rightarrow \Delta A$ associated with each message profile. Let $\Sigma_{i}$ be the set of strategies $\sigma_{i}: T_{i} \rightarrow M_{i}$ of player $i .^{5}$ Then, $\sigma=\left(\sigma_{i}\right)_{i \in N}$ is a strategy profile. Note that $g(\sigma)$ is a Savage act. Let $\Lambda^{\Gamma}=\left[N, T, g,\left(\Sigma_{i}\right)_{i \in N}, \mathcal{E}\right]$ be the game induced by the mechanism $\Gamma$ in the environment $\mathcal{E}$.

A direct mechanism is a mechanism such that $M_{i}=T_{i}, \forall i \in N$. We identify a direct mechanism $\left(\left(T_{i}\right)_{i \in N}, f\right)$ by its outcome function $f$, which is a Savage act. Let $\Lambda^{f}$ be the game induced by the direct mechanism in $\mathcal{E}$. Note that $\Psi_{i}$ is the set of strategies of player $i$ in $\Lambda^{f}$. Let $\psi_{i}^{*}$ be the truthful strategy, i.e., $\psi_{i}^{*}\left(t_{i}\right)=t_{i}, \forall t_{i} \in T_{i}$.

Now we incorporate the fact that the preferences can be menu dependent in the definition of the equilibrium. For any profile of the other players' strategies $\sigma_{-i}$, let $F\left(g, \sigma_{-i}\right)=\left\{g\left(\sigma_{i}, \sigma_{-i}\right) \mid \sigma_{i} \in \Sigma_{i}\right\} . F\left(g, \sigma_{-i}\right)$ is the menu of Savage acts that is available to player $i$ when other players are playing $\sigma_{-i}$.

Definition 2.2. A strategy profile $\sigma^{*}$ is an equilibrium of $\Lambda^{\Gamma}$ if $\forall i \in N$ and $\forall t_{i} \in T_{i}$,

$$
g\left(\sigma^{*}\right) \succeq_{t_{i}}^{F\left(g, \sigma_{-i}^{*}\right)} g\left(\sigma_{i}, \sigma_{-i}^{*}\right), \forall \sigma_{i} \in \Sigma_{i}
$$

Thus, $\sigma^{*}$ is an equilibrium of $\Lambda^{\Gamma}$ if the Savage act generated by $\sigma^{*}$ is maximal for each type of each player in the menu available to that player when other players play according to $\sigma^{*}$.

Fix an environment $\mathcal{E}$. The revelation principle states that for every mechanism $\Gamma$ and for every equilibrium outcome of $\Lambda^{\Gamma}$, there exists a direct mechanism $f$ which induces a game $\Lambda^{f}$ with an outcome-equivalent equilibrium in which all players report their type truthfully. Note that $\left(\psi_{i}^{*}\right)_{i \in N}$ is an equilibrium in $\Lambda^{f}$ if and only if $\forall i \in N$ and $\forall t_{i} \in T_{i}, f \succeq_{t_{i}}^{F(f, i)} f_{\psi_{i}}, \forall \psi_{i} \in \Psi_{i}$.

The next theorem characterizes the maximal domain in which the revelation principle holds.

\section{Theorem 2.3.}

1. If $\mathcal{E}$ is such that $\succeq_{t_{i}}$ satisfies $W C C$ for all $t_{i} \in T_{i}$ and $i \in N$, then the revelation principle holds.

2. If $\succeq_{t_{i}^{\prime}}$ does not satisfy $W C C$, then there exists a $\mathcal{E}=\left(\left(\succeq_{t_{i}^{\prime}},\left(\succeq_{t_{i}}\right)_{t_{i} \neq t_{i}^{\prime}}\right),\left(\succeq_{j}\right)_{j \neq i}\right)$ such that the revelation principle does not hold in $\mathcal{E}$.

Proof.

1. Suppose $\mathcal{E}$ is such that $\succeq_{t_{i}}$ satisfies $W C C$ for all $t_{i} \in T_{i}$ and $i \in N$. Let $\Gamma$ be an

\footnotetext{
${ }^{5}$ We restrict ourselves to pure strategies.
} 
arbitrary mechanism and $\sigma^{*}$ be an equilibrium of $\Lambda^{\Gamma}$. Then $\forall i \in N$ and $\forall t_{i} \in T_{i}$,

$$
g\left(\sigma^{*}\right) \succeq_{t_{i}}^{F\left(g, \sigma_{-i}^{*}\right)} g\left(\sigma_{i}, \sigma_{-i}^{*}\right), \forall \sigma_{i} \in \Sigma_{i} .
$$

Let $F_{i}=F\left(g, \sigma_{-i}^{*}\right)$. First, we argue that $F_{i}=\bigcup_{\xi_{i}^{F_{i}} \in \Xi_{i}^{F_{i}}} F\left(\xi_{i}^{F_{i}}\right)$.

Pick a $f^{\prime} \in F_{i}$. Consider $\xi_{i}^{\prime F_{i}} \in \Xi_{i}^{F_{i}}$ such that $\xi_{i}^{\prime F_{i}}\left(t_{i}\right)=f^{\prime}, \forall t_{i} \in T_{i}$. Then $f^{\prime}=f_{\psi_{i}^{*}}^{\prime}=h_{\psi_{i}^{*}}^{\xi_{i}^{\prime F_{i}}}$ and thus, $f^{\prime} \in F\left(\xi_{i}^{\prime F_{i}}\right)$. So, $F_{i} \subseteq \bigcup_{\xi_{i}^{F_{i}} \in \Xi_{i}^{F_{i}}} F\left(\xi_{i}^{F_{i}}\right)$.

Next, pick a $f^{\prime} \in \bigcup_{\xi_{i}^{F_{i}} \in \Xi_{i}^{F_{i}}} F\left(\xi_{i}^{F_{i}}\right)$. Then $f^{\prime} \in F\left(\xi_{i}^{F_{i}}\right)$ for some $\xi_{i}^{F_{i}} \in \Xi_{i}^{F_{i}}$. Therefore,

$$
\begin{aligned}
f^{\prime} & =h_{\psi_{i}}^{\xi_{i}^{F_{i}}} \text { for some } \psi_{i} \in \Psi_{i} \text { and } \xi_{i}^{F_{i}} \in \Xi_{i}^{F_{i}} \\
\Longrightarrow f^{\prime}(t) & =\xi_{i}^{F_{i}}\left(t_{i}\right)\left(\psi_{i}\left(t_{i}\right), t_{-i}\right), \forall t \in T \\
& =g\left(\sigma_{i}^{t_{i}}\left(\psi_{i}\left(t_{i}\right)\right), \sigma_{-i}^{*}\left(t_{-i}\right)\right), \text { for some } \sigma_{i}^{t_{i}} \in \Sigma_{i}, \forall t \in T \\
& =g\left(\sigma_{i}^{\prime}\left(t_{i}\right), \sigma_{-i}^{*}\left(t_{-i}\right)\right), \forall t \in T,
\end{aligned}
$$

where $\sigma_{i}^{\prime} \in \Sigma_{i}$ is such that $\sigma_{i}^{\prime}\left(t_{i}\right)=\sigma_{i}^{t_{i}}\left(\psi_{i}\left(t_{i}\right)\right), \forall t_{i} \in T_{i}$. Thus, $f^{\prime} \in F_{i}$ and so $\bigcup_{\xi_{i}^{F_{i}} \in \Xi_{i}^{F_{i}}} F\left(\xi_{i}^{F_{i}}\right) \subseteq F_{i}$.

Now, let $f=g\left(\sigma^{*}\right) \in F_{i}$. Therefore, $\forall i \in N$ and $\forall t_{i} \in T_{i}$,

$$
\begin{aligned}
(1) & \Longleftrightarrow f \succeq_{t_{i}}^{F_{i}} f^{\prime}, \forall f^{\prime} \in F_{i} \\
& \Longrightarrow f \succeq_{t_{i}}^{F(f, i)} f_{\psi_{i}}, \forall \psi_{i} \in \Psi_{i},
\end{aligned}
$$

since $F_{i}=\bigcup_{\xi_{i}^{F_{i}} \in \Xi_{i}^{F_{i}}} F\left(\xi_{i}^{F_{i}}\right), f \in F_{i}$ and $\succeq_{t_{i}}$ satisfies $W C C$. Thus, $\left(\psi_{i}^{*}\right)_{i \in N}$ is an equilibrium of $\Lambda^{f}$ and the outcome of this equilibrium is equal to $g\left(\sigma^{*}\right)$.

2. Suppose $\succeq_{t_{i}^{\prime}}$ does not satisfy $W C C$. Then there exist a $F \subseteq \mathcal{F}$ such that $F=$ $\bigcup_{\xi_{i}^{F} \in \Xi_{i}^{F}} F\left(\xi_{i}^{F}\right)$ and a $f \in F$ such that $f \succeq_{t_{i}^{\prime}}^{F} f^{\prime}, \forall f^{\prime} \in F$ but $f_{\psi_{i}^{\prime}} \succ_{t_{i}^{\prime}}^{F(f, i)} f$, for some $\psi_{i}^{\prime} \in \Psi_{i}$.

For all $t_{i} \neq t_{i}^{\prime}$, pick $\succeq_{t_{i}}$ such that,

$$
f \succeq_{t_{i}}^{F} f^{\prime}, \forall f^{\prime} \in F \text {. }
$$

For all $j \neq i$, pick $\succeq_{j}$ such that $\forall t_{j} \in T_{j}$,

$$
f \succeq_{t_{j}}^{F(f, j)} f_{\psi_{j}}, \forall \psi_{j} \in \Psi_{j}
$$

Fix $\mathcal{E}=\left(\left(\succeq_{t_{i}^{\prime}},\left(\succeq_{t_{i}}\right)_{t_{i} \neq t_{i}^{\prime}}\right),\left(\succeq_{j}\right)_{j \neq i}\right)$ to be the environment. 
Define $\Gamma$ to be such that $M_{i}=F \times T_{i}, M_{j}=T_{j}, \forall j \neq i$, and

$$
g\left(\left(f^{\prime}, t_{i}\right), t_{-i}\right)=f^{\prime}\left(t_{i}, t_{-i}\right), \forall\left(f^{\prime}, t_{i}\right) \in F \times T_{i}, t_{-i} \in T_{-i} .
$$

Thus, $\Sigma_{i}=\Xi_{i}^{F} \times \Psi_{i}$ and $\Sigma_{j}=\Psi_{j}, \forall j \neq i$.

We argue that $\sigma^{*}$ such that

$$
\begin{aligned}
\sigma_{j}^{*}\left(t_{j}\right) & =t_{j}, \forall t_{j} \in T_{j}, j \neq i, \text { and } \\
\sigma_{i}^{*}\left(t_{i}\right) & =\left(f, t_{i}\right), \forall t_{i} \in T_{i}
\end{aligned}
$$

is an equilibrium of $\Lambda^{\Gamma}$. Note that $g\left(\sigma^{*}\right)=f$.

$F\left(g, \sigma_{-j}^{*}\right)=F(f, j), \forall j \neq i$. This is because $\Sigma_{j}=\Psi_{j}$, all players other than $j$ announce their type truthfully in $\sigma_{-j}^{*}$ and player $i$ announces $f$ in $\sigma_{i}^{*}$. It follows from (3) that $\forall j \neq i$ and $\forall t_{j} \in T_{j}, g\left(\sigma^{*}\right) \succeq_{t_{j}}^{F\left(g, \sigma_{-j}^{*}\right)} g\left(\sigma_{j}, \sigma_{-j}^{*}\right), \forall \sigma_{j} \in \Sigma_{j}$.

Now we show that $F\left(g, \sigma_{-i}^{*}\right)=\bigcup_{\xi_{i}^{F} \in \Xi_{i}^{F}} F\left(\xi_{i}^{F}\right)$. This is because

$$
\begin{aligned}
& f^{\prime} \in F\left(g, \sigma_{-i}^{*}\right) \\
\Longleftrightarrow & f^{\prime}(t)=g\left(\sigma_{i}\left(t_{i}\right), \sigma_{-i}^{*}\left(t_{-i}\right)\right), \forall t \in T, \text { for some } \sigma_{i} \in \Sigma_{i} \\
\Longleftrightarrow & f^{\prime}(t)=\xi_{i}^{F}\left(t_{i}\right)\left(\psi_{i}\left(t_{i}\right), t_{-i}\right), \forall t \in T, \text { for some } \xi_{i}^{F} \in \Xi_{i}^{F} \text { and } \psi_{i} \in \Psi_{i} \\
\Longleftrightarrow & f^{\prime} \in \bigcup_{\xi_{i}^{F} \in \Xi_{i}^{F}} F\left(\xi_{i}^{F}\right)
\end{aligned}
$$

Thus, $F\left(g, \sigma_{-i}^{*}\right)=\bigcup_{\xi_{i}^{F} \in \Xi_{i}^{F}} F\left(\xi_{i}^{F}\right)=F$. It follows from the hypothesis and (2) that $\forall t_{i} \in T_{i}$,

$$
f \succeq_{t_{i}}^{F} f^{\prime}, \forall f^{\prime} \in F \Longleftrightarrow g\left(\sigma^{*}\right) \succeq_{t_{i}}^{F\left(g, \sigma_{-i}^{*}\right)} g\left(\sigma_{i}, \sigma_{-i}^{*}\right), \forall \sigma_{i} \in \Sigma_{i}
$$

Hence, $\sigma^{*}$ is an equilibrium of $\Lambda^{\Gamma}$ and $g\left(\sigma^{*}\right)=f$. If the revelation principle holds, then $\left(\psi_{i}^{*}\right)_{i \in N}$ must be an equilibrium of $\Lambda^{f}$. However, this is impossible since $f_{\psi_{i}^{\prime}} \succ_{t_{i}^{\prime}}^{F(f, i)} f$.

Remark 2.4. If $\succeq_{t_{i}}$ is menu independent (i.e., there exists a complete relation $\succeq_{t_{i}}^{\prime}$ over $\mathcal{F}$ such that $\forall f, f^{\prime} \in \mathcal{F}$ and $\forall F \subseteq \mathcal{F}$ with $f, f^{\prime} \in F$, we have $f \succeq_{t_{i}}^{F} f^{\prime} \Longleftrightarrow$ $\left.f \succeq_{t_{i}}^{\prime} f^{\prime}\right)$, then $\succeq_{t_{i}}$ satisfies $W C C$. Thus, in particular, if $\succeq_{i}$ is an expected-utility preference then each $\succeq_{t_{i}}$ is menu independent and so it satisfies $W C C$.

Remark 2.5. We cannot strengthen part 2 of Theorem 2.3 because even if $\succeq_{t_{i}^{\prime}}$ does not satisfy $W C C$, there exists a $\mathcal{E}=\left(\left(\succeq_{t_{i}^{\prime}},\left(\succeq_{t_{i}}\right)_{t_{i} \neq t_{i}^{\prime}}\right),\left(\succeq_{j}\right)_{j \neq i}\right)$ such that the 
revelation principle holds in $\mathcal{E}$. To see this, let $\mathcal{F}^{\prime}$ be the set of all Savage acts $f$ such that there exist a $F \subseteq \mathcal{F}$ with $F=\bigcup_{\xi_{i}^{F} \in \Xi_{i}^{F}} F\left(\xi_{i}^{F}\right), f \in F$ and $f \succeq_{t_{i}^{\prime}}^{F} f^{\prime}, \forall f^{\prime} \in F$ but $f_{\psi_{i}^{\prime}} \succ_{t_{i}^{\prime}}^{F(f, i)} f$ for some $\psi_{i}^{\prime} \in \Psi_{i}$. Now, $\mathcal{F}^{\prime} \neq \emptyset$ since $\succeq_{t_{i}^{\prime}}$ does not satisfy $W C C$.

We know that player $i$ has at least two types since for some $f \in \mathcal{F}^{\prime}$, we have $f_{\psi_{i}^{\prime}} \succ_{t_{i}^{\prime}}^{F(f, i)} f$. Pick $t_{i}^{\prime \prime} \in T_{i}$ such that $t_{i}^{\prime \prime} \neq t_{i}^{\prime}$. Let $\succeq_{t_{i}^{\prime \prime}}$ be menu independent and such that $\forall f, f^{\prime} \in \mathcal{F}$,

$$
\begin{array}{ll}
f \sim_{t_{i}^{\prime \prime}} f^{\prime} & \text { if } f, f^{\prime} \notin \mathcal{F}^{\prime} \text { or if } f, f^{\prime} \in \mathcal{F}^{\prime} \\
f \succ_{t_{i}^{\prime \prime}} f^{\prime} & \text { if } f \notin \mathcal{F} \text { and } f^{\prime} \in \mathcal{F} \\
f^{\prime} \succ_{t_{i}^{\prime \prime}} f & \text { if } f \in \mathcal{F} \text { and } f^{\prime} \notin \mathcal{F} .
\end{array}
$$

For all $t_{i} \neq t_{i}^{\prime}, t_{i}^{\prime \prime}$, pick $\succeq_{t_{i}}$ such that it is menu independent. For all $j \neq i$ and $\forall t_{j} \in T_{j}$, pick $\succeq_{t_{j}}$ such that it is menu independent. We show that the revelation principle holds in this environment.

Pick any $f \in \mathcal{F}^{\prime}$. Consider $\psi_{i}^{\prime \prime} \in \Psi_{i}$ such that $\psi_{i}^{\prime \prime}\left(t_{i}\right)=t_{i}^{\prime \prime}, \forall t_{i} \in T_{i}$. Clearly, $f_{\psi_{i}^{\prime \prime}} \notin \mathcal{F}^{\prime}$ since $F\left(f_{\psi_{i}^{\prime \prime}}, i\right)=\left\{f_{\psi_{i}^{\prime \prime}}\right\}$. Therefore, $f_{\psi_{i}^{\prime \prime}} \succ_{t_{i}^{\prime \prime}} f$. There does not exist any mechanism $\Gamma$ such that $\sigma^{*}$, where $g\left(\sigma^{*}\right)=f$, is an equilibrium of $\Lambda^{\Gamma}$; otherwise,

$$
\begin{aligned}
& g\left(\sigma^{*}\right) \succeq_{t_{i}^{\prime \prime}} g\left(\sigma_{i}, \sigma_{-i}^{*}\right), \forall \sigma_{i} \in \Sigma_{i} \\
\Longrightarrow & g\left(\sigma^{*}\right) \succeq_{t_{i}^{\prime \prime}} g\left(\sigma_{i}^{*}\left(\psi_{i}\right), \sigma_{-i}^{*}\right), \forall \psi_{i} \in \Psi_{i} \\
\Longrightarrow & f \succeq_{t_{i}^{\prime \prime}} f_{\psi_{i}^{\prime \prime}} \text {, since } g\left(\sigma^{*}\right)=f \text { and } g\left(\sigma_{i}^{*}\left(\psi_{i}^{\prime \prime}\right), \sigma_{-i}^{*}\right)=f_{\psi_{i}^{\prime \prime}} ; \text { a contradiction. }
\end{aligned}
$$

Now, pick any $f^{\prime} \notin \mathcal{F}^{\prime}$. If there exists a mechanism $\Gamma^{\prime}$ such that $\sigma^{\prime *}$, where $g^{\prime}\left(\sigma^{*}\right)=f^{\prime}$, is an equilibrium of $\Lambda^{\Gamma^{\prime}}$, then $\forall j \in N$ and $\forall t_{j} \in T_{j}$,

$$
\begin{aligned}
& g^{\prime}\left(\sigma^{\prime *}\right) \succeq_{t_{j}}^{F\left(g^{\prime}, \sigma_{-j}^{\prime *}\right)} g^{\prime}\left(\sigma_{j}^{\prime}, \sigma_{-j}^{\prime *}\right), \forall \sigma_{j}^{\prime} \in \Sigma_{j}^{\prime} \\
\Longrightarrow & g^{\prime}\left(\sigma^{\prime *}\right) \succeq_{t_{j}}^{F\left(g^{\prime}, \sigma_{-j}^{\prime *}\right)} g^{\prime}\left(\sigma_{j}^{\prime *}\left(\psi_{j}\right), \sigma_{-j}^{\prime *}\right), \forall \psi_{j} \in \Psi_{j} \\
\Longrightarrow & f^{\prime} \succeq_{t_{j}}^{F\left(g^{\prime}, \sigma_{-j}^{\prime *}\right)} f_{\psi_{j}}^{\prime}, \forall \psi_{j} \in \Psi_{j}, \text { since } g^{\prime}\left(\sigma^{\prime *}\right)=f^{\prime} \text { and } g^{\prime}\left(\sigma_{j}^{\prime *}\left(\psi_{j}\right), \sigma_{-j}^{\prime *}\right)=f_{\psi_{j}}^{\prime} \\
\Longrightarrow & f^{\prime} \succeq_{t_{j}}^{F\left(f^{\prime}, j\right)} f_{\psi_{j}}^{\prime}, \forall \psi_{j} \in \Psi_{j},
\end{aligned}
$$

where the last implication follows for $t_{i}^{\prime}$ since $f^{\prime} \notin \mathcal{F}^{\prime}$ (see the proof of part 1 of Theorem 2.3 to argue that $\left.F\left(g^{\prime}, \sigma_{-i}^{* *}\right) \equiv F_{i}=\bigcup_{\xi_{i}^{F_{i}} \in \Xi_{i}^{F_{i}}} F\left(\xi_{i}^{F_{i}}\right)\right)$ and for all other types of all players since their preferences are menu independent. Thus, the revelation principle holds in this environment.

Next, we provide an example in which the minimax-regret preference relation 
does not satisfy $W C C$ and consequently, the revelation principle does not hold.

Example 2.6. We say that $\succeq_{i}$ is a minimax-regret preference if there exists a $u_{i}$ : $A \times T \rightarrow \Re$ such that $\forall t_{i} \in T_{i}, \forall f, f^{\prime} \in \mathcal{F}$ and $\forall F \subseteq \mathcal{F}$ with $f, f^{\prime} \in F$, we have

$$
\begin{aligned}
& f \succeq_{t_{i}}^{F} f^{\prime} \\
\Longleftrightarrow & \sup _{t_{-i} \in T_{-i}}\left[\sup _{f^{\prime \prime} \in F} \int_{A} u_{i}\left(a, t_{i}, t_{-i}\right) d f^{\prime \prime}\left(t_{i}, t_{-i}\right)-\int_{A} u_{i}\left(a, t_{i}, t_{-i}\right) d f\left(t_{i}, t_{-i}\right)\right] \\
& \leq \sup _{t_{-i} \in T_{-i}}\left[\sup _{f^{\prime \prime} \in F} \int_{A} u_{i}\left(a, t_{i}, t_{-i}\right) d f^{\prime \prime}\left(t_{i}, t_{-i}\right)-\int_{A} u_{i}\left(a, t_{i}, t_{-i}\right) d f^{\prime}\left(t_{i}, t_{-i}\right)\right]
\end{aligned}
$$

Minimax-regret preference need not satisfy $W C C$. Consider the following example. Suppose $N=\{1,2\}, T_{1}=\left\{t_{1}^{1}, t_{1}^{2}\right\}, T_{2}=\left\{t_{2}^{1}, t_{2}^{2}\right\}$ and $A=\{a, b, c\}$. Player 1 has the minimax-regret preference with $u_{1}\left(a, t_{1}^{1}, t_{2}\right)=0, u_{1}\left(b, t_{1}^{1}, t_{2}\right)=1$ and $u_{1}\left(c, t_{1}^{1}, t_{2}\right)=$ $2, \forall t_{2} \in T_{2}$ and $u_{1}\left(a, t_{1}^{2}, t_{2}\right)=u_{1}\left(b, t_{1}^{2}, t_{2}\right)=1$ and $u_{1}\left(c, t_{1}^{2}, t_{2}\right)=0, \forall t_{2} \in T_{2}$.

Let $\psi_{1}^{1}$ be such that $\psi_{1}^{1}\left(t_{1}^{1}\right)=\psi_{1}^{1}\left(t_{1}^{2}\right)=t_{1}^{2} ; \psi_{1}^{2}$ be such that $\psi_{1}^{2}\left(t_{1}^{1}\right)=\psi_{1}^{2}\left(t_{1}^{2}\right)=t_{1}^{1}$; and $\psi_{1}^{3}$ be such that $\psi_{1}^{3}\left(t_{1}^{1}\right)=t_{1}^{2}$ and $\psi_{1}^{3}\left(t_{1}^{2}\right)=t_{1}^{1}$.

Consider $F(f, 1)$ as follows:
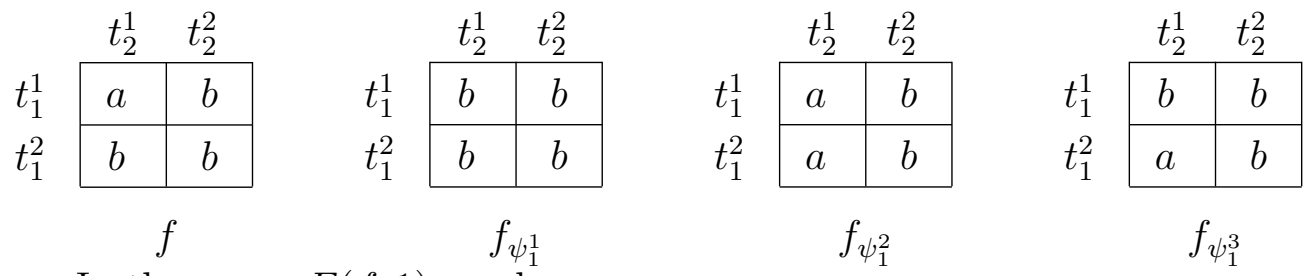

In the menu $F(f, 1)$, we have

$$
\begin{aligned}
& \max _{t_{2} \in T_{2}}\left[\max _{f^{\prime \prime} \in F(f, 1)} u_{1}\left(f^{\prime \prime}\left(t_{1}^{1}, t_{2}\right),\left(t_{1}^{1}, t_{2}\right)\right)-u_{1}\left(f\left(t_{1}^{1}, t_{2}\right),\left(t_{1}^{1}, t_{2}\right)\right)\right]=1 \\
& \max _{t_{2} \in T_{2}}\left[\max _{f^{\prime \prime} \in F(f, 1)} u_{1}\left(f^{\prime \prime}\left(t_{1}^{1}, t_{2}\right),\left(t_{1}^{1}, t_{2}\right)\right)-u_{1}\left(f_{\psi_{1}^{1}}\left(t_{1}^{1}, t_{2}\right),\left(t_{1}^{1}, t_{2}\right)\right)\right]=0
\end{aligned}
$$

Therefore, $f_{\psi_{1}^{1}} \succ_{t_{1}^{1}}^{F(f, 1)} f$.

Define the following Savage acts:

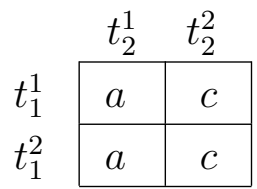

$f_{1}$

\begin{tabular}{|l|l|}
\hline \multicolumn{1}{|c|}{$t_{2}^{1}$} & $t_{2}^{2}$ \\
\hline$a$ & $c$ \\
\hline$a$ & $b$ \\
\hline
\end{tabular}

$f_{2}$

\begin{tabular}{l|c|c|}
\multicolumn{1}{c}{} & \multicolumn{1}{c}{$t_{2}^{1}$} & $t_{2}^{2}$ \\
\cline { 2 - 3 }$t_{1}^{1}$ & $a$ & $c$ \\
\cline { 2 - 3 }$t_{1}^{2}$ & $b$ & $b$ \\
\cline { 2 - 3 } & &
\end{tabular}

$f_{3}$

\begin{tabular}{l|l|l|} 
& \multicolumn{1}{c}{$t_{2}^{1}$} & $t_{2}^{2}$ \\
\cline { 2 - 3 }$t_{1}^{1}$ & $a$ & $b$ \\
\cline { 2 - 3 }$t_{1}^{2}$ & $a$ & $c$ \\
\cline { 2 - 3 } & &
\end{tabular}

$f_{4}$

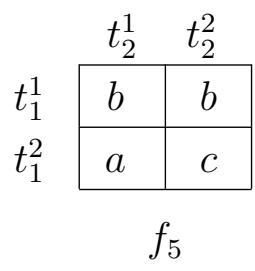

$f_{5}$

Define the menu $F=F(f, 1) \bigcup\left\{f_{1}, f_{2}, f_{3}, f_{4}, f_{5}\right\}$. Pick a $f^{\prime} \in \bigcup_{\xi_{1}^{F} \in \Xi_{1}^{F}} F\left(\xi_{1}^{F}\right)$. Graphically, $f^{\prime}$ has two rows and each row of $f^{\prime}$ can equal any one of the following: 


\begin{tabular}{|l|l|}
\hline$a$ & $b$ \\
\hline
\end{tabular}$\quad$\begin{tabular}{|l|l|}
\hline$b$ & $b$ \\
\hline
\end{tabular}$\quad$\begin{tabular}{|l|l|}
\hline$a$ & $c$ \\
\hline
\end{tabular}

Therefore, $\bigcup_{\xi_{1}^{F} \in \Xi_{1}^{F}} F\left(\xi_{1}^{F}\right)$ contains exactly 9 Savage acts and these are the ones that define $F$. Thus, $F=\bigcup_{\xi_{1}^{F} \in \Xi_{1}^{F}} F\left(\xi_{1}^{F}\right)$.

However, $\forall f^{\prime} \in F$, we have

$$
\max _{t_{2} \in T}\left[\max _{f^{\prime \prime} \in F} u_{1}\left(f^{\prime \prime}\left(t_{1}^{1}, t_{2}\right),\left(t_{1}^{1}, t_{2}\right)\right)-u_{1}\left(f^{\prime}\left(t_{1}^{1}, t_{2}\right),\left(t_{1}^{1}, t_{2}\right)\right)\right]=1
$$

Therefore, $f \succeq_{t_{1}^{1}}^{F} f^{\prime}, \forall f^{\prime} \in F$ but $f_{\psi_{1}^{1}} \succ_{t_{1}^{1}}^{F(f, 1)} f$, which is a violation of $W C C$.

Similarly, we have $f \succeq_{t_{1}^{2}}^{F} f^{\prime}, \forall f^{\prime} \in F$. Now, using the construction in the proof of part 2 of Theorem 2.3 and appropriately defining the preference of player 2 (e.g., player 2 also has minimax-regret preference with $u_{2}\left(a, t_{1}, t_{2}^{n}\right)=u_{2}\left(b, t_{1}, t_{2}^{n}\right), \forall t_{1} \in$ $\left.T_{1}, \forall n=1,2\right)$, it is easy to show that the revelation principle fails in this example.

Finally, we provide an example in which the preference of each type a player is menu dependent and it satisfies $W C C$.

Example 2.7. Suppose $N=\{1,2\}, T_{1}=\left\{t_{1}^{1}, t_{1}^{2}\right\}, T_{2}=\left\{t_{2}\right\}$ and $A=\{a, b\}$. Then $\Delta A=\left\{(p, 1-p) \in \Re_{+}^{2}\right\}$, where $p$ is the probability of outcome $a$; i.e., $\Delta A$ is the unit-simplex in $\Re_{+}^{2}$. Let $t^{1}=\left(t_{1}^{1}, t_{2}\right)$ and $t^{2}=\left(t_{1}^{2}, t_{2}\right)$. Thus, $T=\left\{t^{1}, t^{2}\right\}$.

For any Savage act $f$ and any state $t$, let $f^{a}(t)$ be the probability of outcome $a$ in state $t$. Thus, geometrically, a Savage act $f=\left[f\left(t^{1}\right), f\left(t^{2}\right)\right]$ is a pair of points $f\left(t^{1}\right)=\left(f^{a}\left(t^{1}\right), 1-f^{a}\left(t^{1}\right)\right)$ and $f\left(t^{2}\right)=\left(f^{a}\left(t^{2}\right), 1-f^{a}\left(t^{2}\right)\right)$ on the unit-simplex in $\Re_{+}^{2}$.

For any menu $F$, let $\bar{p}^{F}\left(t^{n}\right), n=1,2$, be defined as follows:

$$
\bar{p}^{F}\left(t^{n}\right)=\frac{1}{2}\left(\inf _{f \in F} f^{a}\left(t^{n}\right)+\sup _{f \in F} f^{a}\left(t^{n}\right)\right)
$$

$\bar{p}^{F}\left(t^{n}\right)$ is thus the "mid-point" of the menu in state $t^{n}$.

For all $n=1,2$, the preference $\succeq_{t_{1}^{n}}^{F}$ is defined as follows: for all $f, \tilde{f} \in F$, we have

$$
f \succeq_{t_{1}^{n}}^{F} \tilde{f} \Longleftrightarrow\left|f^{a}\left(t^{n}\right)-\bar{p}^{F}\left(t^{n}\right)\right| \leq\left|\tilde{f}^{a}\left(t^{n}\right)-\bar{p}^{F}\left(t^{n}\right)\right|
$$

Each type of player 1 thus displays extremeness aversion, which Tversky and Simonson (1993, p. 1183) describe as follows, "In some situations, [...] decision makers may evaluate options in terms of their advantages and disadvantages, defined relative to 
each other $[. .$.$] As a consequence, options with extreme values within an offered set$ will be relatively less attractive than options with intermediate values." Similarly, in the example, the further away a Savage act is from the "mid-point" of the menu in state $t^{n}$, the less it is "liked" by type $t_{1}^{n}$ of player 1.

By definition, $\succeq_{t_{1}^{n}}$ is menu dependent. Let $f$ be any Savage act. It is straightforward to show that $\bar{p}^{F(f, 1)}\left(t^{n}\right)=\frac{1}{2}\left(f^{a}\left(t^{1}\right)+f^{a}\left(t^{2}\right)\right)$. Therefore, for any $\tilde{f} \in F(f, 1)$, we have

$$
\left|\tilde{f}^{a}\left(t^{n}\right)-\bar{p}^{F(f, 1)}\left(t^{n}\right)\right|=\frac{1}{2}\left|f^{a}\left(t^{1}\right)-f^{a}\left(t^{2}\right)\right|
$$

Hence, for any Savage act $f$, type $t_{1}^{n}$ of player 1 is indifferent between all Savage acts in the menu $F(f, 1)$. Therefore, $\succeq_{1}^{n}$ satisfies $W C C$ for all $n=1,2$.

\section{Conclusion}

We extended the domain of preferences to include menu-dependent preferences and characterized the maximal subset of this domain in which the revelation principle holds. The condition that characterizes this maximal domain is what we called weak contraction consistency for all types of all players. We argued that weak contraction consistency is a weaker version of the well-known contraction consistency. Although weak contraction consistency is a weak condition, we showed that an important menu-dependent preference relation, minimax-regret preference, lies outside the maximal domain. We also gave an example in which the preference of each type of a player is menu dependent and satisfies weak contraction consistency.

\section{Appendix}

A type of a player plays only in the interim stage. Therefore, one might argue that a type of a player should "care" about interim lotteries that specify an outcome for each realization of other player's types instead of Savage acts which are ex-ante lotteries. In that case, we need to make three changes to our model: first, we must assume that each type of each player has a preference relation over each interim menu, which is a set of interim lotteries; second, we must define an equilibrium concept, say interim equilibrium, that incorporates the interim menu that is available to each type of each player; and third, we must restate the revelation principle as follows: for every interim equilibrium of any mechanism, there exists a a direct mechanism with an 
outcome-equivalent interim equilibrium in which all types of all players report their respective types truthfully. Here, we show that from any such preference relation over interim menus we can derive a preference relation over menus such that the set of interim equilibria of any mechanism is the same as the set of equilibria (as defined in Section 2) of that mechanism. Then it is easy to show that all the results of Section 2 hold if this derived preference relation over menus satisfies their respective premises.

An interim lottery for type $t_{i}$ of player $i$ is a function $l_{t_{i}}: T_{-i} \rightarrow \Delta A$ and let $\mathcal{L}_{t_{i}}$ be the set of such functions. An interim menu for type $t_{i}$, denoted by $L_{t_{i}}$, is a subset of $\mathcal{L}_{t_{i}}$. Now, let's suppose that each type $t_{i}$ of each player $i$ has a complete preference relation $\tilde{\succeq}_{t_{i}}^{L_{t_{i}}}$ over each $L_{t_{i}} \subseteq \mathcal{L}_{t_{i}}$. Let $\tilde{\succeq}_{t_{i}}=\left(\check{\check{L}}_{t_{i}}^{L_{t_{i}}}\right)_{L_{t_{i}} \subseteq \mathcal{L}_{t_{i}}}$ and $\tilde{\succeq}_{i}=\left(\check{\check{\beth}}_{t_{i}}\right)_{t_{i} \in T_{i}}$.

Pick any mechanism $\Gamma$ and consider the game $\tilde{\Lambda}^{\Gamma}=\left[N, T, g,\left(\Sigma_{i}, \check{\succeq}_{i}\right)_{i \in N}\right]$ induced by the mechanism. For any strategy profile $\sigma$, the interim menu available to type $t_{i}$ of player $i$ is $L_{t_{i}}\left(\sigma_{-i}\right)=\left\{g\left(m_{i}, \sigma_{-i}\right) \mid m_{i} \in M_{i}\right\}$. We say that a strategy profile $\sigma^{*}$ is an interim equilibrium of $\tilde{\Lambda}^{\Gamma}$ if $\forall i \in N$ and $\forall t_{i} \in T_{i}$,

$$
g\left(\sigma_{i}^{*}\left(t_{i}\right), \sigma_{-i}^{*}\right) \check{\succeq}_{t_{i}}^{L_{t_{i}}\left(\sigma_{-i}^{*}\right)} g\left(m_{i}, \sigma_{-i}^{*}\right), \forall m_{i} \in M_{i}
$$

First, we derive a complete preference relation $\succeq_{t_{i}}=\left(\succeq_{t_{i}}^{F}\right)_{F \subseteq \mathcal{F}}$ from $\check{\succeq}_{t_{i}}$. For any Savage act $f$, define $\left.f\right|_{t_{i}}: T_{-i} \rightarrow \Delta A$ as $\left.f\right|_{t_{i}}\left(t_{-i}\right)=f\left(t_{i}, t_{-i}\right), \forall t_{-i} \in T_{-i}$. For any menu $F \subseteq \mathcal{F}$, define $\left.F\right|_{t_{i}}=\left\{\left.f\right|_{t_{i}} \mid f \in F\right\}$. By definition, $\left.f\right|_{t_{i}} \in \mathcal{L}_{t_{i}}$ and $\left.F\right|_{t_{i}} \subseteq \mathcal{L}_{t_{i}}$. Finally, define $\succeq_{t_{i}}^{F}$ as follows: $\forall f, f^{\prime} \in F$, let $\left.\left.f \succeq_{t_{i}}^{F} f^{\prime} \Longleftrightarrow f\right|_{t_{i}} \check{\succeq}_{t_{i}}^{\left.F\right|_{t_{i}}} f^{\prime}\right|_{t_{i}}$. The preference relation $\succeq_{t_{i}}^{F}$ is complete because $\check{\succeq}_{t_{i}}^{\left.F\right|_{t_{i}}}$ is complete. Let $\succeq_{i}=\left(\succeq_{t_{i}}\right)_{t_{i} \in T_{i}}$.

Next, consider the mechanism $\Gamma$. We argue that a strategy profile $\sigma^{*}$ is an equilibrium of $\Lambda^{\Gamma}=\left[N, T, g,\left(\Sigma_{i}, \succeq_{i}\right)_{i \in N}\right]$ if and only if $\sigma^{*}$ is an interim equilibrium of $\tilde{\Lambda}^{\Gamma}=\left[N, T, g,\left(\Sigma_{i}, \check{\succeq}_{i}\right)_{i \in N}\right]$. Notice that $L_{t_{i}}\left(\sigma_{-i}\right)=\left.F\left(g, \sigma_{-i}\right)\right|_{t_{i}}$. Therefore, $\forall i \in N$ and $\forall t_{i} \in T_{i}$,

$$
\begin{aligned}
& g\left(\sigma_{i}^{*}\left(t_{i}\right), \sigma_{-i}^{*}\right) \tilde{\succeq}_{t_{i}}^{L_{t_{i}}\left(\sigma_{-i}^{*}\right)} g\left(m_{i}, \sigma_{-i}^{*}\right), \forall m_{i} \in M_{i} \\
\Longleftrightarrow & \left.\left.g\left(\sigma^{*}\right)\right|_{t_{i}} \check{\succeq}_{t_{i}}^{F\left(g, \sigma_{-i}^{*}\right) \mid t_{i}} g\left(\sigma_{i}, \sigma_{-i}^{*}\right)\right|_{t_{i}}, \forall \sigma_{i} \in \Sigma_{i} \\
\Longleftrightarrow & g\left(\sigma^{*}\right) \succeq_{t_{i}}^{F\left(g, \sigma_{-i}^{*}\right)} g\left(\sigma_{i}, \sigma_{-i}^{*}\right), \forall \sigma_{i} \in \Sigma_{i} .
\end{aligned}
$$

\section{References}

Cabrales, A., Serrano, R., 2007. Implementation in adaptive better-response dynamics. Working Paper 2007-10, Department of Economics, Brown University. 
Chernoff, H., 1954. Rational selection of decision functions. Econometrica 22, 422443.

Dasgupta, P., Hammond, P., Maskin, E., 1979. The implementation of social choice rules: Some results on incentive compatibility. Review of Economic Studies 46, $185-216$.

Eliaz, K., 2002. Fault-tolerant implementation. Review of Economic Studies 69, 589610.

Huber, J., Payne, J.W., Puto, C., 1982. Adding asymmetrically dominated alternatives: Violations of regularity and the similarity hypothesis. Journal of Consumer Research 9, 90-98.

Hurwicz, L., 1986. On the implementation of social choice rules in irrational societies. In: Heller, W.P., Ross, R.M., Starret, D.A. (Eds.). Social choice and public decision making: Essays in honor of Kenneth J. Arrow. Cambridge: Cambridge University Press, 75-96.

Myerson, R., 1979. Incentive compatibility and the bargaining problem. Econometrica $47,61-73$.

Sen, A., 1971. Choice functions and revealed preference. Review of Economic Studies $38,307-317$.

Sen, A., 1993. Internal consistency of choice. Econometrica 61, 495-521.

Sen, A., 1994. The formulation of rational choice. American Economic Review (Papers and Proceedings) 84, 385-390.

Sen, A., 1997. Maximization and the act of choice. Econometrica 65, 745-779.

Simonson, I., Tversky, A., 1992. Choice in context: Tradeoff contrast and extremeness aversion. Journal of Marketing Research 29, 281-295.

Tversky, A., Simonson, I., 1993. Context-dependent preferences. Management Science 39, 1179-1189.

Savage, L. J., 1951. The theory of statistical decision. Journal of American Statistical Association 46, 55-67.

von Neumann, J., Morgenstern, O., 1944. Theory of Games and Economic Behavior. Princeton: Princeton University Press. 